\title{
Measuring quality of life: an integrative approach
}

\author{
Adigam Barlybaev ${ }^{1,3}$, Azamat Barlybaev $^{2}$, Zulfiya Ishnazarova ${ }^{1,3 *}$, Diyaz Ishnazarov $^{3}$ and \\ Inna Sitnova ${ }^{1,3}$ \\ ${ }^{1}$ Institute of strategic research of the Republic of Bashkortostan, Sibay branch, Kutuzov Srt., 1, \\ 453837 Sibay, Russia \\ ${ }^{2}$ Institute of strategic research of the Republic of Bashkortostan, Kirov Srt., 15, 450008 Ufa, Russia \\ ${ }^{3}$ Bashkir state University, Sibay Institute (branch), Belov Srt., 21, 453838 Sibay, Russia
}

\begin{abstract}
The article analyzes the indicators of the quality of life and substantiates the need for their rethinking. Global changes in the economy and society, scientific achievements keep current the issue of improving the indicators of the well-being of the population and methods of calculating them with an emphasis on identifying the final result. In particular, there is a need to reassess the consolidated indicators, namely the place of gross domestic product and other economic indicators in assessing the quality of life as the basis of people's well-being. It is concluded that the methods of assessing the quality of life mainly take into account the material side of well-being, which can be quantified, but the subjective side of the state of people - expectations, emotional state, experiences, spiritual state, etc., completely fall out of sight. Such a predominance of the material and visible issues, materialized in measuring and assessing the standard of living does not give a complete picture of the quality of life of the population, which does not contribute to the development of adequate goals, means, methods and mechanisms for the improvement thereof.
\end{abstract}

\section{Introduction}

The quality of life of the population reflects the material, spiritual and emotional satisfaction of the people, and therefore the problem of its measuring and evaluating always remains relevant. Currently, there are more than 150 ways to measure and assess the quality of life, while the emphasis is on its various aspects in different countries [1-4].

There are constant discussions on measurement techniques, and for the most part they are related to the fact that the current methods assess only the material side, which can be quantified, and the subjective side is practically not assessed - expectations, emotional state, experiences of a person and the population, i.e. political, social - spiritual and psychological components of well-being.

Thus, in 2009, a report of the Commission on Key Indicators of Economic Activity and Social Progress, led by Nobel laureates Joseph Stiglitz and Amartya Sen, was released,

\footnotetext{
*Corresponding author: zmsalikhova@mail.ru
} 
which proposed replacing the assessment of gross domestic product (GDP) with an indicator of the quality of life as the main criterion for the economic development of the society. This report also highlighted the key components of the concept of "quality of life": material living conditions, health, educational level and the availability of various skills, personal activities, political voice and civil rights, social ties and relationships, current and future state of the environment, economic and physical security. A year later, in 2010, there was published a book titled "Mis-measuring Our Lives. Why GDP doesn't Add Up" by Joseph Stiglitz, Amartya Sen, Jean-Paul Fitoussi, where they propose to revise the assessment of the well-being of the population, the quality of life and make some changes. In particular, they write that "in the world of globalization, there may be large differences between the incomes of citizens of a certain country and the indicator of domestic production, but the former one is obviously more directly related to measuring the wellbeing of the citizens" [5]. The authors recommend, when measuring the well-being of the population, to shift the emphasis to indicators of social and environmental status, psychophysiological state of the population. At the same time, they call for a complete abandonment of gross domestic product and other indicators of production, but show that "a gap has formed between the information contained in aggregate GDP data and indicators that are important for the well-being of ordinary people, and this gap continues to grow" $[5]$.

\section{Materials and Methods}

The article used the fundamental and applied works of domestic and foreign scientists involved in assessing the quality of life, production and economic development, including the main impetus for writing this paper was the above-mentioned "Mis-measuring Our Lives. Why GDP doesn't Add Up" and the World Happiness Report by John F. Helliwell, Richard Layard and Jeffrey D. Sachs for 2019 [6]. The rationale for theoretical positions and conclusions was carried out on the basis of the application of general scientific methods (analysis, synthesis, comparison), specific methods (generalization and interpretation of scientific data, assessment of socio-economic indicators and the development of the population's quality of life), methods of dialectical logic, statistics and sociology.

\section{Results and Discussion}

As recommendations and suggestions, the authors of the above studies offer as follows:

1. When assessing the material well-being of the population, one shall give preference to indicators of income and consumption, rather than to production indicators.

2. When assessing the quality of life and well-being of the population, one should proceed from the conditions and results of the life of households.

3. Income and consumption of households is the most important indicator of their material well-being, just as for an enterprise the balance sheet is the basis for calculating the indicators of its financial state.

4. More adequate ways of measuring the results of non-market activities of households should be developed, since they often produce goods and services for their own consumption, and these benefits are not taken into account in assessing income and production, although they form a separate aspect of economic activity.

5. When assessing the quality of life, both objective and subjective aspects are important. Objective aspects include the level of education, health, environmental conditions, personal activity and others, subjective ones are a personal assessment of one's 
life, the psychological and emotional state of a person, expectations from the future and others.

6. "Indicators of the quality of life in all aspects under consideration should fully assess an inequality. It is necessary to assess inequality in the quality of life of individuals, socio-economic groups, people with different genders and different generations, paying special attention to those types of inequality that have recently arisen, for example, in connection with emigration "[7].

7. In assessing the quality of life, the environmental aspect is important, which deserves separate consideration on the basis of a well-chosen set of adequate indicators.

The authors base their assumptions and recommendations on the analysis of gross domestic product and real disposable incomes of the USA, France, Norway. There are differences between the volume of production and the income of the population, while the gross domestic product characterizes "the final result of the production activity of the resident economic units, which is measured by the value of goods and services produced by these units for final use" [8]. As an example, the income of the Irish population is given, which decreases in comparison with the country's GDP. In this case, GDP growth reflects the increasing share of profits received by foreign investors. However, this increase in profits does not strengthen the purchasing power of the population. Therefore, the fact that the GDP is growing every year is not so important for the population, since they want to know if they have become better off. "Moreover, the import prices develop in a completely different way than the export ones, and these changes in relative prices should be taken into account when assessing the standard of living" [5]. The authors also compare GDP at constant prices and Norway's real net national disposable income. "The numbers show the discrepancy between the real income and production in Norway, an oil-rich OECD country whose income grew faster than GDP when oil prices rose. For many developing countries, whose export prices have tended to fall relative to import ones, the opposite is true" (Figure 1).

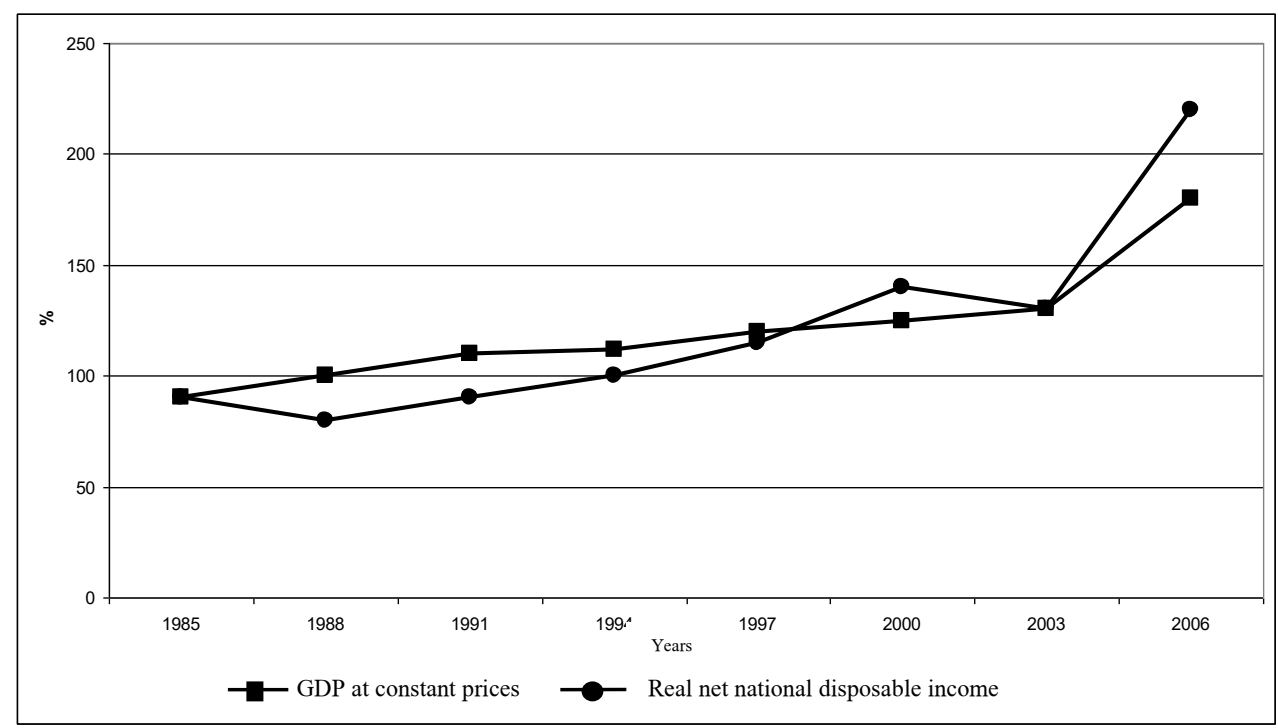

Fig. 1. Norway's GDP and disposable income

Thus, gross domestic product is an indicator that is most often used to assess the development of a country's economy, but it primarily measures market production, although it is often considered as a measure of economic welfare. Mixing the two concepts can lead to misinformation about whether people are doing well and lead to bad policy 
decisions. At one time, the monetary measurement of the country's economic condition was well developed, but this approach has a certain omission - the addition of quantities of things that are extremely heterogeneous in nature. The amount of the goods and services produced does not represent who they are consumed by: households, enterprises or the state. In this regard, certain difficulties arise:

1. Certain goods and services may not be priced (for example, the government provides free health insurance, or if households themselves raise their children), which raises the question of how to evaluate these services.

2. And even established market prices may deviate from the underlying societal assessment: "when the consumption or production of certain products affects the society as a whole, the price people pay for these products will differ from their value for the whole society" [5]. For example, the environmental damage caused by certain types of production or consumption, and it is not reflected in market prices.

Many goods and services change over time or lose their relevance and value (computer salons for independent use, Internet cards, landline phones), new ones appear instead of them, with different functions and quality, sales through the Internet are developing. In this regard, difficulties arise in collecting data and assessing their quality. Although it is extremely important for measuring the real income and the real consumption, one of the determinants of human well-being.

We analyzed the dynamics of the gross domestic product and real disposable cash income of the Russian Federation (Figure 2.)

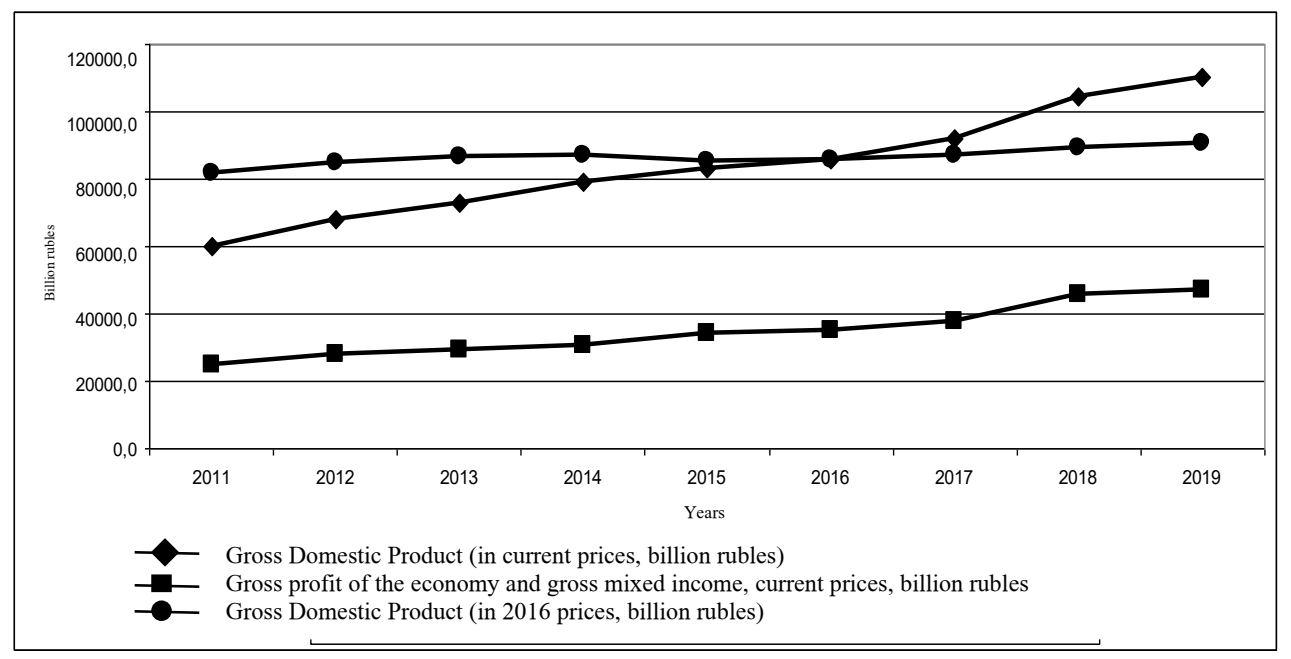

Fig. 2. GDP, gross profit of the economy, gross mixed income of the Russian Federation

Indeed, according to the graph, we can see that the gross domestic product, like the gross profit of the economy and the gross mixed income of the Russian Federation, has a positive trend throughout the analyzed period [7]. However, the real disposable cash income of the population of Russia from 2012 to 2016 had a negative trend, while this indicator most accurately reflects the characteristics of the well-being of the population. Real disposable cash income is the amount of money that remains with a person by deducting the mandatory payments (Fig. 3). 


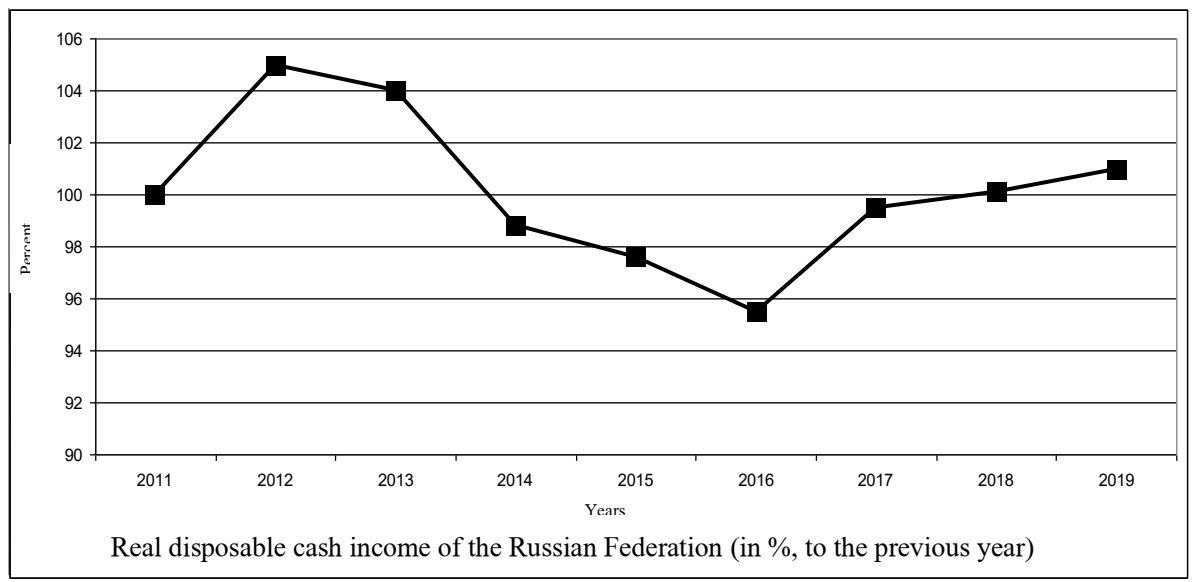

Fig. 3. Real disposable cash income of the Russian Federation

Another assumption is that when assessing the well-being of the population, it is necessary to take into account the environmental aspects of life. Since this directly affects the health of the population. "Emission of harmful substances into the atmosphere, wastewater can enter the human body later through food, water and even during breathing. A person experiences a harmful influence every day, which affects the well-being and the general condition of a person" [8]. At present, the problem of water and air pollution occurs in small settlements that do not have any polluting production on their territory, not to mention large industrial cities. Therefore, this factor must also be taken into account when assessing the quality of life of the population.

The analysis of performance indicators and environmental aspects of sustainable development show that the values of indicators of both production and the ecological environment are growing (Figure 4). However, in the case of an increase in production and consumption waste generation, this will negatively affect the ecological well-being of the territory and the well-being of the population (Figure 5).

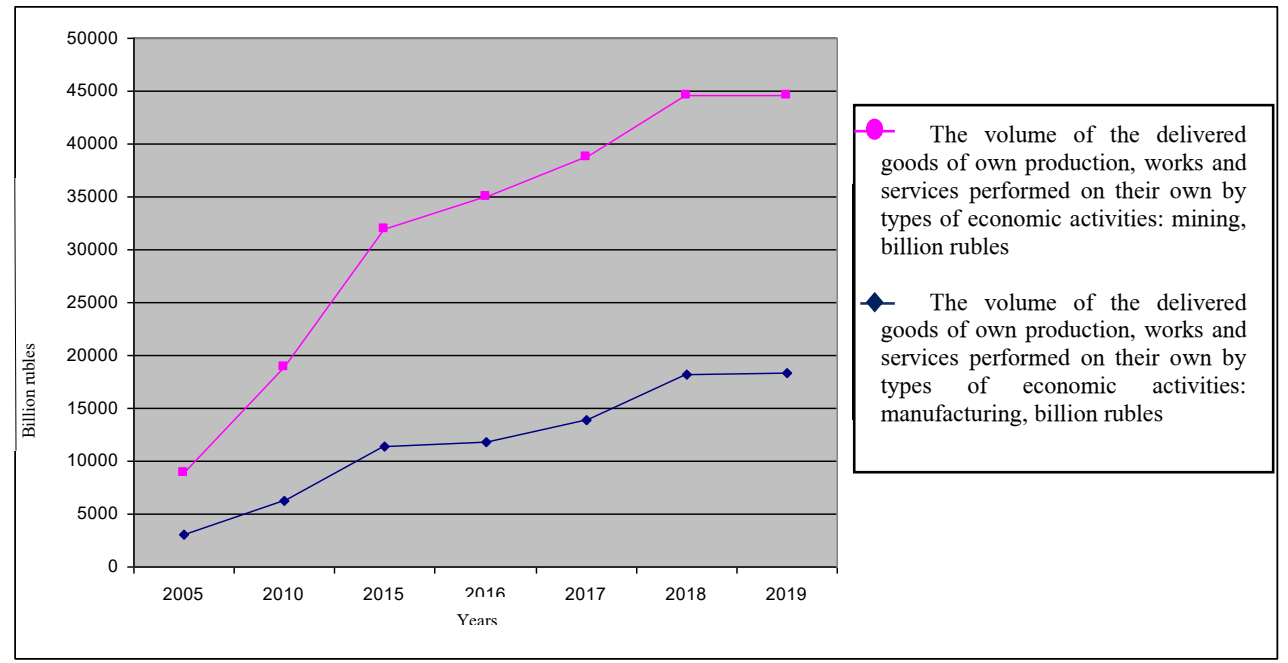

Fig. 4. The volume of the delivered goods of own production, works and services performed on their own by types of economic activities: mining, manufacturing 
The volume of the delivered goods of own production, works and services performed on their own by type of economic activity, manufacturing and mining since 2005 have increased 4.5 times and almost 7 times, respectively. At the same time, production and consumption wastes were generated more than 2 times in the period from 2005 to 2019.

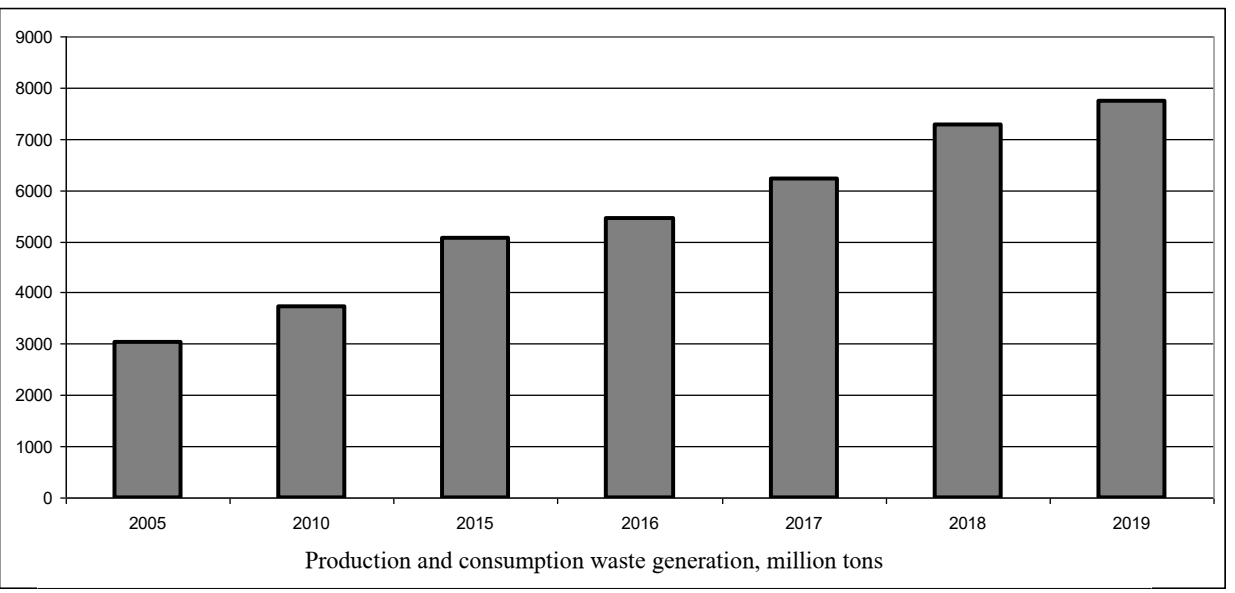

Fig. 5. Production and consumption waste generation

Another factor in the well-being of the population is the expectations, emotional state, experiences of a person and the population. Some countries have introduced the so-called "happiness index" to assess this very factor. In some countries, the issue of happiness is resolved at the highest level, for example, Ministries of Happiness are established (Bhutan, UAE, India), whose functions include monitoring the level of satisfaction with the life of the population, work on youth and educational programs, investment projects in the field of sports, entertainment and image infrastructure.

According to the World Happiness Report, Russia ranked 68th out of 104 in the ranking of the happiest countries in 2016-2018 [6]. The top five places are: Finland, Denmark, Norway, Iceland, the Netherlands. The main indicators being analyzed and used in this report are social support, freedom, corruption, GDP per capita, and the expectation of a healthy lifestyle.

A subjective assessment of life is carried out by specialists of the "Levada Center" Analytical Center, which specializes in the research using various survey methods. According to the results of their research in 2019, slightly more than half of the 1600 surveyed citizens of Russia are not sure about the future (about 51\%) [9, 10]. And back in $2004,70 \%$ of the respondents were confident in the future but $30 \%$ were not. Throughout the entire subsequent period to the present day, the share of those who are confident in the future (among the respondents) has steadily decreased, the share of those who are not confident in their future has increased. The indicators of optimism also indicate a decrease in positive expectations - political optimism is equal to 1 point, economic optimism -1.4 points. The research carried out by the center shows that until 1999, the optimism of citizens did not reach even 1 point. The highest level of positive expectations of citizens was recorded in 2000-2008: the indicator of political optimism was 3.4 points, the indicator of economic optimism was 2.3 points. The question "What feelings, in your opinion, have become stronger recently in you personally?" was asked in 2019 , and the most frequently noted feelings were hope, resentment for their people, fatigue and indifference, followed by a sense of confidence in the future, pride in their people, self-esteem. The question "What are you most afraid of?" was asked, and the most frequently noted answers were the fears of illness of loved ones and children, war, loss of working capacity, poverty and natural 
disasters. Fifty-four percent of the respondents look with concern and apprehension at their future, and $58 \%$ with concern about the future of Russia. Only $17 \%$ of those surveyed believe that they are currently experiencing the most difficult times, $30 \%$ are sure that they are already behind and $47 \%$ believe that difficult times are still ahead. The respondents note the presence of some social tension between the rich and the poor people in the country. They also believe that it is not the best time now for savings, while if they make savings, they prefer to keep them in banks than in foreign currency or precious metals.

Thus, according to the center's research, a significant part of the country's population does not feel happy, despite the growing indicators of the economy and production. The epidemiological situation associated with the COVID-19 pandemic further exacerbated the unfavorable dynamics of certain indicators of the quality of life of people, and at the same time increased the pessimistic mood of the country's population.

\section{Conclusion}

It is obvious that there is no direct and unambiguous relationship between the development of the economy and production, on the one hand, and the growth of the population's wellbeing, on the other. When using the economy and production as the indicators of the quality of life, a certain array of unaccounted aspects is revealed, which distorts the real state of things. In particular, it should be borne in mind that, first, an improvement in GDP and production indicators does not necessarily lead to a mirror increase in the income and wellbeing of the population. Secondly, an increase in the volume of goods and services produced may be accompanied by an even greater increase in harmful emissions on the environment, worsening the environment and public health. Thirdly, the well-being and optimism of the citizens are determined not only by good indicators of socio-economic development, but also by many difficult-to-measure factors of a social, psychological and spiritual nature, established through the study of the subjective opinion of citizens. Each of these aspects is of no less importance than others, and only a holistic perception of all aspects ultimately determines the quality of life of people. Therefore, the solution to the problem under study can be the development of additional calculation methods that allow measuring the quality of life as a system of indicators that integrates a multitude of interrelated objective and subjective factors into a single whole.

\section{Acknowledgments}

The work was prepared as a result of the financial support for the implementation of the "Sustainable development of the Bashkir Trans-Urals as a unified socio-ecologicaleconomic system" state program by GANU "Institute for Strategic Studies of the Republic of Bashkortostan" for 2020 (supervisor - Suyundukov Ya.T.)

\section{References}

1. Z.M. Ishnazarova, D.U. Ishnazarov, Ya.T. Suyundukov, Bulletin of the Altai Academy of Economics and law, 4-2, 200 (2020)

2. D.U. Ishnazarov, Z.M. Ishnazarova, U.A. Barlybaev, Ya.T. Suyundukov Regional economy: theory and practice, 12, 2259 (2019)

3. N.V. Trofimova, Municipal economy, 1 (49), 2 (2012)

4. M.I. Kolenov, Scientific works of the North-West Institute of Management RANEPA. 2 (24), 284 (2016) 
5. D. Stiglitz, A. Sen, J.-P. Fitoussi, Misjudging Our Lives: Why Doesn't GDP Make Sense? Report of the Commission on measuring economic performance and social progress. 113 (2016)

6. John F. Helliwell, Richard Layard and Jeffrey D. Sachs. World Happiness Report. UN Sustainable Development Solutions Network, 140 (2019)

7. Rosstat: Consolidated accounts, https://rosstat.gov.ru

8. G. V. Kalashnikova, A. M. Minigaleeva Young scientist, 12, 560 (2015)

9. Levada center: Public opinion-2019, https://levada.ru

10. L.N. Ovcharova, M.D. Krasilnikova, A.I. Pishnyak, Monitoring of the socio-economic situation and social well-being of the population, 32 (2020) 